\title{
Egocentric localization of the visual horizontal in normal and labyrinthine-defective observers as a function of head and body tilt
}

BRANT CLARK AND ASHTON GRAYBIEL

SAN JOSE STATE COLLEGE AND NAVAL AEROSPACE MEDICAL INSTITUTE, PENSACOLA, FLORIDA

Perception of the visual horizontal by observers in five different combinations of head and body position was studied to determine the effect of 20-degree body tilts. Both normal and labyrinthine-defective observers made five settings to the visual horizontal for each condition using a goggle device which presented a collimated line of light to the right eye while the other eye was covered. The results showed no significant constant errors in the settings by either group, and it is suggested that the absence of the. E-phenomenon was due primarily to adequate contact cues and kinesthetic cues. The data also make it clear that vestibular information is not required for veridical perception of the visual horizontal under these experimental conditions.

This study is concerned with the perception of the visual horizontal in normal and labyrinthinedefective (L-D) Os under five combinations of head and body position. It has been known for over 100 years that when $O$ is passively tilted away from the gravitational vertical, his perception of the visual horizontal is subject to constant errors (Miller, Fregly, van den Brink, \& Graybiel, 1965; Miller \& Graybiel, 1966; Werner, Wapner, \& Chand1er, 1951; Witkin \& Asch, 1948). Posturally induced distortion of the visual vertical has also been reported recently in humans and pigeons (Thomas \& Lyons, 1966). It has been shown that both the direction and the amount of these errors vary with body position, the most commonly reported finding being the E-phenomenon which is the apparent displacement of a vertical, luminous line in darkness in the direction of small bodily tilts from the vertical. The opposite effect, the A-phenomenon, results from large bodily tilts and a vertical luminous line appears to be displaced opposite to the direction of the bodily tilt. Most of these studies have been made with O seated, but Witkin and Asch (1948) have reported simllar results with $O$ standing. More recently it has been shown that other factors than body position per se contribute to the effect. Werner, Wapner, and Chandler (1951) have reported that the E-phenomenon is significantly increased if a seated $O$ tilts his own body rather than being tilted passively in a chair. Day and Wade (1966) have reported aftereffects following prolonged head tilt in seated Os. The present study explored the perception of the visual horizontal in normal and $L-D$ Os while they stood and maintained their head and body in five combinations of alignment with the gravitational vertical and 20 degrees of tilt.

\section{Observers}

\section{METHOD}

Five normal and five deaf, L-D Os were studied. The normal Os were medical students who showed normal responses to caloric stimulation (McLeod \& Meek, 1963) and to an ataxia test (Graybiel \& Fregly, 1966). The L-D Os had acquired their deafness in childhood as a sequelae of meningitis and showed abnormal responses to the caloric and ataxia tests. All the Os had had experience in making observations in rotating devices and in the use of the goggle device to measure the perception of the visual horizontal.

\section{Apparafus}

The $O$ viewed a collimated luminous line in a self-contained apparatus mounted in a goggle which he held snugly in position before his eyes. The apparatus presented the red luminous line to the right eye while light was completely occluded from the left eye. The luminous line could be rotated either clockwise or counterclockwise by means of a knurled knob which was easily reached by either $O$ or $E$. The digital readout was in degrees of deviation from the horizontal axis of the device itself. The goggle was easily held in place by $O$, and a flexible rubber fitting prevented light leaks under the operating conditions used.

Three spirit levels were used to monitor the alignment of the goggle apparatus, $O^{\prime} s$ head, and $O$ 's body. The first level was located on the goggle itself, a second on a band over O's head, and a third on his back.

\section{Procedure}

All measurements were made with $O$ standing, with his head and body in one of the five different combinations of positions with respect to gravity. Each trial was begun by an $E$ who offset the line from the horizontal, and $O^{\prime}$ 's task was merely to set it to the gravitational horizontal. Three Es were required for every trial: One observed the level on $O$ 's back to monitor his body position; a second monitored the levels on the head and on the goggle and offset the luminous line before each setting; 
Table 1.

Mean constant error in degrees in setting a luminous line to the horizontal in darkness by normal and labyrinthine-defective 0 s.*

\begin{tabular}{|c|c|c|c|c|c|}
\hline & & & $\begin{array}{l}\mathrm{rmals} \\
\mathrm{l}=5\rangle\end{array}$ & & $\begin{array}{l}\text { Ds } \\
=5 \text { ) }\end{array}$ \\
\hline Condition & & Series & Series & Series & Series \\
\hline 1. Head \& body erect & Mean & -0.5 & -0.3 & -0.1 & +0.6 \\
\hline & S.D. & 1.9 & 2.8 & 2.5 & 1.1 \\
\hline II. Head \& body tilted together & Mean & +0.5 & 0.0 & -1.4 & +0.2 \\
\hline & S.D. & 5.3 & 3.4 & 5.2 & 3.9 \\
\hline III. Head tilted \& body erect & Mean & -1.5 & -0.1 & -0.5 & +0.9 \\
\hline & S.D. & 5.1 & 2.5 & 5.1 & 1.7 \\
\hline IV. Head erect \& body tilted & $\begin{array}{l}\text { Mean } \\
\text { S.D. }\end{array}$ & $\begin{array}{r}+0.5 \\
1.4\end{array}$ & $\begin{array}{r}+0.5 \\
1.8\end{array}$ & $\begin{array}{r}+0.8 \\
2.5\end{array}$ & $\begin{array}{r}+1.1 \\
1.7\end{array}$ \\
\hline V. Head \& body tilted opposite & Mean & +0.6 & +0.9 & +1.7 & -0.2 \\
\hline & S.D. & 3.1 & 3.3 & 3.7 & 8.3 \\
\hline
\end{tabular}

* $+=$ clockwise deviation; $-=$ counterclockwise deviation

and the third made and recorded the settings. No setting was recorded unless both monitors were satisfied that the proper head and body positions were maintained to within a half degree. An attempt was made to make the readings promptly on all trials because two of the position were somewhat uncomfortable to maintain for prolonged periods. Nevertheless, $O$ was permitted to take as much time as he felt he needed to make an accurate setting. The light was turned off while the line was offset. $O$ made five successive settings to the horizontal for each of the following five conditions: I. head and body erect; II. head and body tilted 20 degrees to the right; III. head tilted 20 degrees to the right and body erect; IV. head erect and body tilted 20 degrees to the right; $V$. head tilted 20 degrees to the right and body tilted 20 degrees to the left. Subsequently, a second series of observations was made with the right and left tilts reversed with respect to the first series. An interval of several hours elapsed between the two series.

\section{RESULTS}

\section{Constant Errors}

The data were analyzed first to note any constant errors in setting to the visual horizontal associated with body position and second with respect to the average error from the gravitational horizontal without taking account of the direction of the error. For the normal os the constant error varied from +0.9 to -1.5 degrees for all five conditions and the two series (Table 1). An inspection of the constant errors makes it clear that these errors were all very small when compared to those found in other similar studies (Miller, Fregly, van den Brink, \& Graybiel, 1965; Miller \& Graybiel, 1966; Werner, Wapner, \& Chandler, 1951; Witkin \& Asch, 1948). Furthermore, the direction of the mean setting was not clearly related to the direction of bodily tilt. Similarly, the $L-D$ Os produced very small constant errors which varied from +1.7 to -1.4 degrees and also were not consistently related to the direction of the head or body tilt. Furthermore, an analysis of variance of each of the two series of observations for both groups showed no difference between the five body conditions and no difference between the two groups. The $p$ values in every case were greater than 0.25 . It should be noted that comparisons were not attempted across the two series of trials for the E-phenomenon because it was not possible to make an unequivocal decision whether to relate the setting of the line to the head or the body position. The data for the constant errors can be summarized by saying that since the constant errors do not differ significantly from zero, the E-phenomenon did not occur under the conditions of this experiment for either the normal or L-D Os.

\section{Average Errors}

An analysis of the average errors was made by combining the data for similar body tilts and disregarding the direction of the setting (Table 2). An analysis of variance for these average errors revealed no significant difference between the normal and the L-D Os ( $p>0.25)$; however, there was a significant difference across the five body positions $(p<0.01)$. Individual comparisons were then made between the five head and body positions using a difference $t$. For the normals Condition $V$ (head 20 degrees in one direction and body 20 degrees in the other) showed a significantly greater $(p \leq 0.02)$ average error than Condition I (head and body erect) and Condition IV (head erect and body tilted). There were no significant differences among any of the other conditions. For the L-Ds, again Condition V produced a mean average error greater than Condition I $(p<0.05)$. There were no other significant differences. The primary findings for the average errors, then, was that only when the head was tilted in one direction and the body in the other direction was the average error significantly greater than when the head and body were both erect.

\section{DISCUSSION}

The primary finding of this experiment was that

Table 2

Mean average error in degrees in setting a luminous line to the horizontal in darkness by normal and labyrinthine-defective Os.

\begin{tabular}{|c|c|c|c|c|}
\hline & & $\begin{array}{c}\text { Normals } \\
(\mathrm{N}=5)\end{array}$ & $\begin{array}{l}\mathrm{L}-\mathrm{Ds}_{\mathrm{s}} \\
(\mathrm{N}=5)\end{array}$ & Difference \\
\hline \multicolumn{5}{|l|}{ Condition } \\
\hline \multirow[t]{2}{*}{ I. Head \& body erect } & Mean & 2.1 & 1.7 & \\
\hline & S.D. & 1.7 & 0.7 & -0.4 \\
\hline \multirow[t]{2}{*}{ II. Head \& body tilted together } & Mean & 3.2 & 3.3 & \\
\hline & S.D. & 1.6 & 2.3 & +0.1 \\
\hline \multirow[t]{2}{*}{ III. Head tilted \& body erect } & Mean & 3.3 & 2.3 & \\
\hline & S.D. & 1.0 & 1.3 & -1.0 \\
\hline \multirow[t]{2}{*}{ IV. Head erect \& body tilted } & Mean & 2.2 & 2.0 & \\
\hline & S.D. & 1.3 & 0.8 & -0.2 \\
\hline \multirow[t]{2}{*}{ V. Head \& body tilted opposite } & Mean & 4.1 & 3.6 & \\
\hline & S.D. & 0.9 & 1.3 & -0.5 \\
\hline
\end{tabular}


there was no significant constant error in the perception of the visual horizontal for any of the various combinations of head and body position for either group. It is particularly noteworthy that in Condition II, in which the head and body were tilted in the same direction, head and body positions were identical with the head and body positions typically reported as producing the E-phenomenon; i.e., the setting to the visual horizontal would be in a direction opposite to the direction of the tilt of the head and body (Witkin \& Asch, 1948). Constant errors have also been reported for L-Ds during passive tilt (Miller \& Graybiel, 1966). It is also of importance to note that, at first glance, these results would appear to be in direct conflict with the data of Werner, Wapner, and Chandler (1951) who reported that the constant error increased when an observer actively tilted his head and body 15 degrees and 30 degrees. Interpolating from their data, we would find that supported tilts of 20 degrees would be expected to produce about 3.5 degrees of the E-phenomenon and unsupported tilts of the same amount, about 5.6 degrees.

In considering the differences between this study and the earlier studies, several methodological differences should be noted. In the present experiment: (1) $O$ actively tilted his body from the waist and the head from the shoulders rather than being passively supported. (2) $O^{\prime}$ 's feet were firmly planted on the horizontal floor. (3) $O$ was not supported in any way. (4) $O$ perceived his head and/or body as being tilted away from the gravitational vertical. (5) O set a collimated luminous line viewed monocularly, while in earlier studies (Werner, Wapner, \& Chandler, 1951; Witkin \& Asch, 1948) O viewed the line binocularly at a distance of about $5 \mathrm{ft}$ and $E$ made the settings on direction from the 0 .

In view of these marked differences in methods of testing, the differences in the results are less surprising, but they raise the question regarding the specific cues which make the more veridical perception possible. The lack of a difference between the normals and the L-Ds makes it clear that vestibular information is not crucial in producing these more veridical results. It is suggested that the absence of the E-phenomenon under the conditions of this experiment was due primarily to two rich sources of information available to Os in this experiment. First, the feet were firmly planted on a solid horizontal surface and thus gave unequivocal contact cues to the gravitational horizontal. Additional data on this point have been reported by
Hewes and Spady (1964) in their studies of locomotion in simulated lunar gravity fields. Their Os attributed certain difficulties in locomotion to the reduction of pressure cues to the feet. Thomas and Lyons (1966) have also reported evidence that contact cues from the feet are of importance in visual perception. They reported that there was an induced distortion of the visual vertical when human observers "... perceived as vertical an inclination of the bar in the direction toward which the floor was sloped." Second, there were clear kinesthetic cues from the legs, body, and neck, giving information regarding the amount of tilt of the body. The tactual cues from the feet would appear to be of particular importance in the light of the findings of Werner, Wapner, and Chandler (1951), which show that kinesthetic cues associated with active body tilt increase the constant error. These results give further evidence that the E-phenomenon occurs only under very limited experimental conditions.

\section{References}

Day, R. H. , \& Wade, N. J. Visual spatial aftereffect from prolonged head-tilt. Science, 1966, 154, 1201-1202.

Graybiel, A., \& Fregly, A. R. A new quantitative ataxia test battery. Acta oto-laryngol., Stockholm, 1966, 61, 292-312.

Hewes, D. E., \& Spady, A. A., Jr. Evaluation of a gravity-simulation technique for studies of man's self-locomotion in lunar environment. NASA TN D-2176. Washington, D. C.: National Aeronautics and Space Administration, 1964.

McLeod, M. E., \& Meek, J. C. A threshold caloric test: Results in normal subjects. NSAM-834. NASA R-47. Pensacola, Florida: Naval School of Aviation Medicine, 1962.

Miller, E. F., II, Fregly, A. R., van den Brink, G., \& Graybiel, A. Visual localization of the horizontal as a function of body tilt up to $+90^{\circ}$ from gravitational vertical. NSAM-942. NASA R-93. Pensacola, Florida: Naval School of Aviation Medicine, 1965.

Miller, E. F., I, \& Graybiel, A. Role of otolith organs in the perception of horizontality. Amer. J. Psychol., 1966, 79, 24-37.

Thomas, D. R., \& Lyons, J. The interaction between sensory and tonic factors in the perception of the vertical in pigeons. Percept. \& Psychophys., 1966, 1, 93-95.

Wemer, H., Wapner, S., \& Chandler, K. A. Experiments on sensorytonic field theory of perception. II. Effect of supported and unsupported tilt of the body on the visual perception of verticality. J. exp. Psychol., 1951, 42, 346-350.

Witkin, H. A., \& Asch, S. E. Studies in space orientation: III. Perception of the upright in the absence of a visual field. $J$, exp. Psychol., 1948, 38, 603-614.

\section{Note}

1. This research was conducted under the sponsorship of the Offlce of Advanced Research and Technology, National Aeronautics and Space Administration, Order R-93. Opinions or conclusions contained in this report are those of the authors and do not necessarily reflect the views or endorsement of the Navy Department.

(Accepted for publication August 15, 1967.) 